\title{
La conquista de una frontera. Mentalidades y tecnologías en las vías de comunicación en el desierto de Atacama ${ }^{1}$
}

\author{
José Antonio González Pizarro²
}

\begin{abstract}
RESUMEN
El artículo revisa de qué forma se fue estructurando la conquista por el hombre del espacio desértico, centrándose especialmente en el marco temporal que cubre 1880-1960, dando cuenta de los antecedentes previos. Importa destacar cómo del espontaneísmo inicial prehispánico, se pasa a una racionalidad tanto de la complementariedad entre las altas y bajas tierras, para seguidamente observar las ideologías que guiarán el esfuerzo mayor estatal en la conectividad del páramo. En tal sentido, se esquematiza el tránsito desde las huellas precolombinas hasta la aparición de la carretera panamericana, como de igual modo cómo se planteó el tendido de las líneas ferroviarias particulares y estatales. Seguidamente, se examina la transformación de las caletas, en muelles y en los puertos fiscales, sin dejar de lado los inicios de la explotación del espacio aéreo y su infraestructura.
\end{abstract}

Palabras clave: Desierto de Atacama, ferrocarril, caminos, puertos.

\begin{abstract}
This paper reviews the ways in which man structured the conquering of desert spaces, mainly focusing on the 1880-1960 time framework, including previous data. It is important to highlight how, from initial pre- Hispanic spontaneity, man gets to the rationality of both high and low land complementarily to then observe the ideologies that will lead to greater state efforts to connect the area. In this sense, traffic is schematized from pre Columbus tracks to the building of the Pan-American Highway, together with how private and state railways were planned. Next, how wharfs changed into docks and then state ports is examined including the beginnings of the exploitation of air space and its infrastructure.
\end{abstract}

Key words: Atacama desert, railways, road, ports.

1 Proyecto Fondecyt 1051093 "La emergencia del pensamiento regional en el norte grande de Chile. Conflictos interétnicos y nacionalismos en la sociedad regional contemporánea". Artículo recibido el 7 de marzo de 2008 y aceptado el 19 de junio de 2008.

\footnotetext{
Doctor en Historia por la Universidad de Navarra. Profesor Titular de la Universidad Católica del Norte, Escuela de Derecho, Antofagasta (Chile). E-mail: jagonzal@ucn.cl
} 
El epígrafe precedente encierra una concepción de la relación entre el Hombre y la naturaleza; o mejor dicho, entre la cultura y el medio ambiente.

La historiografía de los Annales cifró en la geografía una de las claves para comprender la historia, como lo demostraron Lucien Febvre, Marc Bloch y Fernand Braudel. Este último, en su formulación teórica del tiempo en la historia, la "larga duración", situaba el de la coacción geográfica, "el hombre prisionero de los climas... la persistencia de las rutas y de los tráficos" (Braudel, 1970: 71). En su primera obra mayor (Braudel, 2005: I: 35), trabajó magistralmente los múltiples factores geográficos que incidieron en los asentamientos humanos, comercio, visiones, haciéndonos notar cuáles eran los límites humanos de la ocupación y significación del espacio y la necesaria -e imprecisa- conceptualización de la montaña. A su vez, los geógrafos apuntaban a situar la importancia de los hechos culturales en el espacio, Roger Dion con la "géographie humaine rétrospective" y E. Gilbert abría las posibilidades de la "Historical Geography", que cultivarían con interesantes aportes teóricos el sueco Thorsten Hagerstrand, con su "three sets of constraints", posibilitando la comprensión de los procesos de difusión, o H. Darby, enfatizando el elemento histórico en la geografía, donde determinadas cuestiones históricas debían ser estimadas fenómenos geográficos (Baker, 2003). La importancia de la cultura en la geografía fue enfatizada por Carl Sauer y Donald Worster, entre otros.

La interrogante de Braudel por la noción de montaña, se planteó también en el espacio geográfico del norte chileno. En el lenguaje castellano, el desierto dice relación con desertar que proviene de desertus, que significa "abandonado" o "desierto" y, de ahí, la noción próxima de despoblado que emplearon los cronistas hispanos del siglo XVI y que se utilizó hasta el siglo XIX. Las otras ideas o expresiones afines hacen converger el sentido biogeográfico con el lenguaje coloquial, páramo, yermo, pampa (Quintanilla, 1977), que recogen miradas culturales sobre el espacio, definido por los elementos constitutivos de su superficie -ca- rencia de pluviosidad, sequedad, fuerte oscilación térmica, ausencia de vegetación arbórea- los que reforzaron la imagen de inhóspito sin mayor interés para la vida humana, como lo expusiera R. A. Philippi, en su viaje por el desierto entre 1853-1854 (Philippi, 1860). Constituyó una verdad entre las cosas naturales del espacio y su entendimiento. Aquello fundamentó la transitoriedad del hombre y su recorrido fue estimado desolador. Pero no fue esta idea/ imagen la que gatilló la recepción de la mecánica y la tecnología motriz en el desierto. Hubo de constituirse otra realidad. Y este vino para el minero chileno y el capitalista europeo del desvelamiento de la otra realidad no "objetiva" en lo superficial, la aletheia: el desocultamiento de la otra "verdad" del desierto: la riqueza minera de su subsuelo. Ahora, sí, con la posibilidad de transformar aquella área en ecúmene. La noción de la otra realidad/verdad fue la establecida por las culturas originarias de la precordillera que establecieron en el desierto el itinerario del tránsito de las caravanas que unió la costa y las tierras altas bajo una concepción cósmica del espacio.

Podemos distinguir en tales sistemas cognitivos, visiones distintas sobre la naturaleza y la cultura. Una naturalista-determinista, que condicionó la lectura de los cronistas y exploradores pioneros de la república; una pragmático-utilitarista, insuflada por la idea de progreso y dominio del hombre sobre la naturaleza, mediante la técnica y lo productivo de sus recursos y una cósmico-sagrada, propia de las concepciones precolombinas de la relación entre el hombre y la naturaleza (Glacken, 1973). Este corpus ideológico que ya se había debatido en la antigüedad clásica, a partir de la antinomia entre physis y teoría o nomos (Grinzer, 1992). Klaus Eder hará mención de tres tipos de construcción social de la naturaleza: cognitive, normative and symbolic construction of nature (Eder, 1996), donde el segundo se asociará con el impulso capitalista y la necesidad del señorío humano sobre la naturaleza.

En lo que nos interesa subrayar, esta visión normativa o pragmático-utilitarista, no solo alteró el paisaje natural sino su propia designación, matizando el significado quechua de pampa y haciendo confluir lo ocul- 
to/visible: los mantos calicheros dieron lugar a las oficinas salitreras. Capitalismo económico y liberalismo político fueron los soportes ideológicos y de acciones practicadas de individuos y sociedades regionales asentados en el desierto provocando la consiguiente mutación de la relación cultura-naturaleza. Fue la marca de la historia sobre el espacio geográfico. La pampa en general fue asumida como el "escenario" de los hechos históricos. Su humanización abrió la constitución del "paisaje" de las salitreras y su conectividad con el litoral -dependiendo del recurso minero y su ley- y alterando la morfología del paisaje natural (Sauer, 1925) con las "tortas" del relave calichero. Cambios que se originaron desde la formulación de una aprehensión cognoscitiva del espacio, donde lo ambiental se confundió con la producción. Aquello constituyó la aplicación de nociones de organización tanto espacial como temporal (Baker, 2003): el agotamiento de un yacimiento, veta o estaca minera supuso el desmantelamiento de la cultura material -oficina salitrera completa, campamento y usinas-, líneas férreas, estaciones, etc. El hombre volvía a desertar.

A esta concepción de la ocupación de la tierra -de dominación- donde no hubo límites a la explotación de sus recursos, significó no solo la concreción de una historia de la minería, los ferrocarriles y otras vías de comunicación, sino una historia de un medio ambiente construido, traducido de modo sintético, en una forma de vida en el desierto (González Pizarro, 2003; Garcés Feliú, 1999) y, también de una historia ambiental (Worster, 1989) que, en el caso que nos ocupa, refiere, en su dimensión endógena, la incidencia del uso consuntivo del agua para la actividad minera y ferroviaria, en desmedro de las actividades agrícolas del altiplano, que contribuyeron al forraje tanto del arrieraje argentino hacia la pampa salitrera como de las recuas de mulas de las propias oficinas salitreras y, en su dimensión exógena, por ejemplo, de la importación de madera de pino de oregón para los "durmientes" de las líneas ferroviarias, casas de la administración o por la vinculación del nitrato de potasio, movido por trenes hacia los puertos y transportados por barcos, hacia los suelos en vías de agotamiento en Norteamérica (Sauer, 1956).
Para comprender el despliegue humano sobre el desierto y la conectividad de sus comunicaciones, habrá que sopesar que tales estructuras de mentalidades en la relación cultura-naturaleza, constituyeron representaciones sociales (Moscovici, 1979), que mediante los procesos de "anclaje" transformó -por medio de construcción de categorías- lo desconocido en familiar (la locución "empampado" es gráfica en tal sentido) y de la "objetivación", los productos del pensamiento en realidades físicas.

Aquellas representaciones sociales también alteraron los "imaginarios sociales" sobre el desierto (González Pizarro, 2008), y posibilitaron afectar tanto los conceptos como las imágenes que poseyeron los individuos y las instituciones en el proceso de la conectividad de las vías de comunicación en el desierto.

El desierto de Atacama asumió entonces diversas ideas-fuerza en las representaciones sociales a lo largo de los siglos XIX y XX. Y con ellas, los factores que repercutieron en su conectividad entre centros de producción, puertos y mercados.

El área natural cedió paso en su transformación por la cultura a la conformación de un área cultural, singular en el país, reconocida por el predominio del complejo económico minero, de plata, salitrero y cuprero (Sauer, 1941).

A medida que el esfuerzo pionero de capitalistas y mineros movido por la iniciativa privada cedió paso gradualmente a la intervención del Estado, se pudo ir observando que la orientación y objetivos de la conectividad asumían no solo la gravitación económica sino que también la urgencia de la integración física regional y las conveniencias de comunicaciones con los países vecinos.

Si nos aproximamos a lo temporal de este proceso de conectividad, podemos distinguir tres etapas muy marcadas:

1) Lo existente antes de 1880 en el área:

2) Lo realizado entre 1880 hasta 1930; y

3) Lo ejecutado entre 1930 y 1960. 
En esta esquematización se constata que en el periodo desde 1880 hasta 1930 hay una preeminencia de la sociedad civil y municipal por enlazar los tendidos de caminos y ferroviarios desde la perspectiva del interés comercial y particular donde el Estado apoya con variadas leyes las concesiones solicitadas y refuerza el ordenamiento político-administrativo de la provincia en 1888 y las vinculaciones de los departamentos y conexiones viales con las estacas mineras en general. Aquello se reflejó en la implementación de los muelles de empresas y particulares en las urbes portuarias de Antofagasta, Taltal y Tocopilla.

A partir de 1930 se dibuja con mayor énfasis la intervención del Estado -que previamente se había preocupado de los estudios para el mejoramiento de los muelles y de los eventuales molos fiscales- en lo que concierne a una política vial, teniendo como finalidad la integración de los espacios interiores de la provincia, jerarquizando los trazados viales, camineros y portuarios.

El territorio en sí también fue apreciado desde la singularidad de espacio reivindicado/anexionado, y como espacio de frontera en su amplia acepción. Repárese la transformación de "sociedad de fronteras" en una "sociedad regional", donde conductas sociales fueron antitéticas a la sociedad agraria tradicional. José Victorino Lastarria (Lastarria, 1871) exclamará que los habitantes del desierto eran "Ios nuevos yankees" de América del Sur.

Todo esto conllevó a definir una relación distinta entre el hombre y la naturaleza en el norte de Chile.

\section{El andar incesante del Hombre. Desde los senderos a los caminos internacionales}

La etapa anterior a la preeminencia de la industria del salitre en la zona permite asumir los ingentes esfuerzos de varios cientos de años que el hombre destinó a relacionarse con el páramo. Los primeros hombres que se arriesgaron a deambular por el territorio, abriendo los surcos de las huellas pioneras, se localizaron entre los años 8.000 y 1.800 a. C.; fue la movilidad arcaica. Posteriormente, bandas pedestres dieron lugar a la movilidad transicional. Más tarde, se implementó la movilidad horizontal norte-sur-norte, conectando la precordillera chilena (San Pedro de Atacama) con la alta puna del sector argentino. Con ello se dio paso al proceso de transhumancia con los sectores trasandinos, abriendo rutas que formarán parte del complejo patrón de la movilidad andina bajo el concepto de "movimiento giratorio" (Núñez y Dillehay, 1995), que comprometió rutas en las tierras altas, entre las tierras altas-costa y entre tierras altas-selvas y viceversa (transhumancia, verticalidad, complementariedad ecológica, intercambio y movilidad semisedentaria).

Las vías ocupadas comunicaron a distintos señoríos del noroeste argentino con los oasis de San Pedro de Atacama, por ejemplo, la quebrada de Purmamarca fue usada desde antiguo para unir Jujuy con el norte de Chile, principalmente el trayecto actual de San Pedro de Atacama-Calama-Antofagasta (Ruiz, 1998), que constituye el antecedente más remoto de la conectividad entre ambos países, todavía vigente en la actualidad.

El advenimiento del Incario alteró esa red, mediante los denominados "Caminos del Inca".

El sur del territorio al área del desierto y la puna de Atacama correspondía al Collasuyo en la división administrativa del Tiwantinsuyu. El Inca Tupac Yupanqui en la segunda mitad del siglo XV construyó el denominado "Camino del Inca" que, en lo que nos interesa subrayar, comprendió dos secciones: una que atravesaba el desierto de Atacama y otra por la región Valliserrana. La del desierto de Atacama tuvo en San Pedro de Atacama su punto de llegada o de partida con relación al sur de Chile. Este camino corría por la margen del salar de Atacama hasta Tilopozo y, desde ahí, apoyado en norias y vegas aisladas, discurría en los topónimos de Puquios, Pajonal, Río Frío, Vegas de Incahuasi, Aguas del Juncal, Agua del Carrizo, Doña Inés, Agua del Panul, hasta conectar con la finca de Chañaral hasta extenderse hasta el río Copiapó. 
El trazado del "Camino del Inca" en el desierto de Atacama se caracterizaba por tramos rectos en distancias de hasta treinta kilómetros y cuando debía enfrentar accidentes orográficos importantes, principalmente quebradas profundas, los constructores y usuarios emplearon subidas en zigzag (Iribarren y Bergholz, 1971; Stehberg, 1995; Raffino, 2006).

La conquista española reorientó el servicio de las vías con vista a la conectividad con la riqueza de plata de la Villa de Potosí, en la Audiencia de Charcas (Bolivia) y, además, aprovecharon de reglamentar su uso y cuidado (González Pizarro, 2006). El Mapa Geográfico de América Meridional, realizado por orden de la Corona española por Juan de la Cruz Cano y Olmedilla, en 1775, consignó el denominado "Camino real" que unía a San Pedro de Atacama con Copiapó.

Entre los siglos XVII y XVIII las intensas relaciones mercantiles estrecharon los contactos entre los actuales territorios de Bolivia, Chile y Argentina, y gravitó en la densidad del tráfico de los caminos. El movimiento de grupos de personas desde Bolivia privilegió los lugares de Chiuchiu y Calama, mientras que los de Salta y Tucumán prefirieron San Pedro de Atacama (Martínez, 1982).

Las antiguas rutas que servían de complementariedad ecológica y económica entre las tierras altas y las bajas mantuvieron su vigencia en la Colonia. Una de ellas era la que unía la ensenada de Cobija con el interior andino pasando por Chacance. En su trayecto alcanzaba a Calama, Chiuchiu, San Pedro de Atacama, antes de acometer el paso por la puna hasta la provincia de Lipes. Esta vieja ruta caravanera -ya noticiada en el siglo XVI- en su trayecto desde Cobija a Caspana dejó testimonios de sus usuarios con una variada distribución de geoglifos.

También el desierto fue recorrido desde su extremo meridional costero en tiempos coloniales y republicanos. El sendero se extendía desde Taltal o desde Paposo y unía los puntos de Hueso Parado (Taltal), Cachiyuyal (próximo a Paposo), Cachinal de Tierra, Aguadita, Barras, Punta Negra, Zorras, Pajonal, Puquios, Tilopozo, Quitana, Tambillo y San Pedro de Atacama (Núñez, 1984: II).

Cabe destacar que los oasis del área atacameña estaban conectados a través de senderos con todos los puntos cardinales. Prueba de ello fueron las vías desde Calama hasta Pica, en la región de Tarapacá. O los que desde la costa Ilegaban hasta Lípez y La Paz, sea a través de Calama-Chiuchiu o por San Pedro de Atacama. O bien, desde San Pedro de Atacama por Socompa hasta Antofagasta de la Sierra. Reconocido en su época fue el Ilamado "camino de Atacama", que desde la costa de Antofagasta proseguía por Monte Jara, Salar del Carmen, la Casa de Lata, Casa de Palo, Sur de Cerro Negro hasta San Pedro de Atacama (Figura $\mathrm{N}^{\circ} 1$ ).

Al establecerse por el gobierno de Bolivia los asentamientos de Cobija o Puerto Lamar hacia fines del decenio de 1820, se planteó la necesidad de reconocer formalmente las vías que debían unirlo con el altiplano. Cubrir la distancia de 188 leguas desde Lamar o Cobija hasta Potosí, por medio de un correo a pie, demoraba aproximadamente 16 días. Incluso se había realizado el trayecto hacia Oruro exigiendo solo 13 días (Cajías, 1975). El recorrido era asistido por maestros de postas que percibían derechos de peaje de un real por mula de carga y medio real por cada dos burros (Arce, 1930). Hacia mediados de 1840 se constituyó el uso de carretas para la vía desde Cobija al interior.

Hacia 1851 José María Dalence, en su "Bosquejo Estadístico de Bolivia", aportó noticias sobre las innumerables praderas, llamadas "potreros", donde se criaba ganado mayor y menor, que había entre el tránsito desde San Pedro de Atacama con dirección hacia Tarapacá como con destino a Copiapó.

El ingeniero chileno Alejandro Bertrand pudo reconocer diversos caminos en sus estudios del desierto y discutir las demarcaciones de localidades y rutas de los mapas levantados durante el siglo XIX (Bertrand, 1885). 
Figura $\mathrm{N}^{\mathrm{o}} 1$

TRÁFICO DE RUTAS PREHISPÁNICAS ENTRE TIERRAS ALTAS Y LA COSTA, VIGENTE DURANTE LA COLONIA

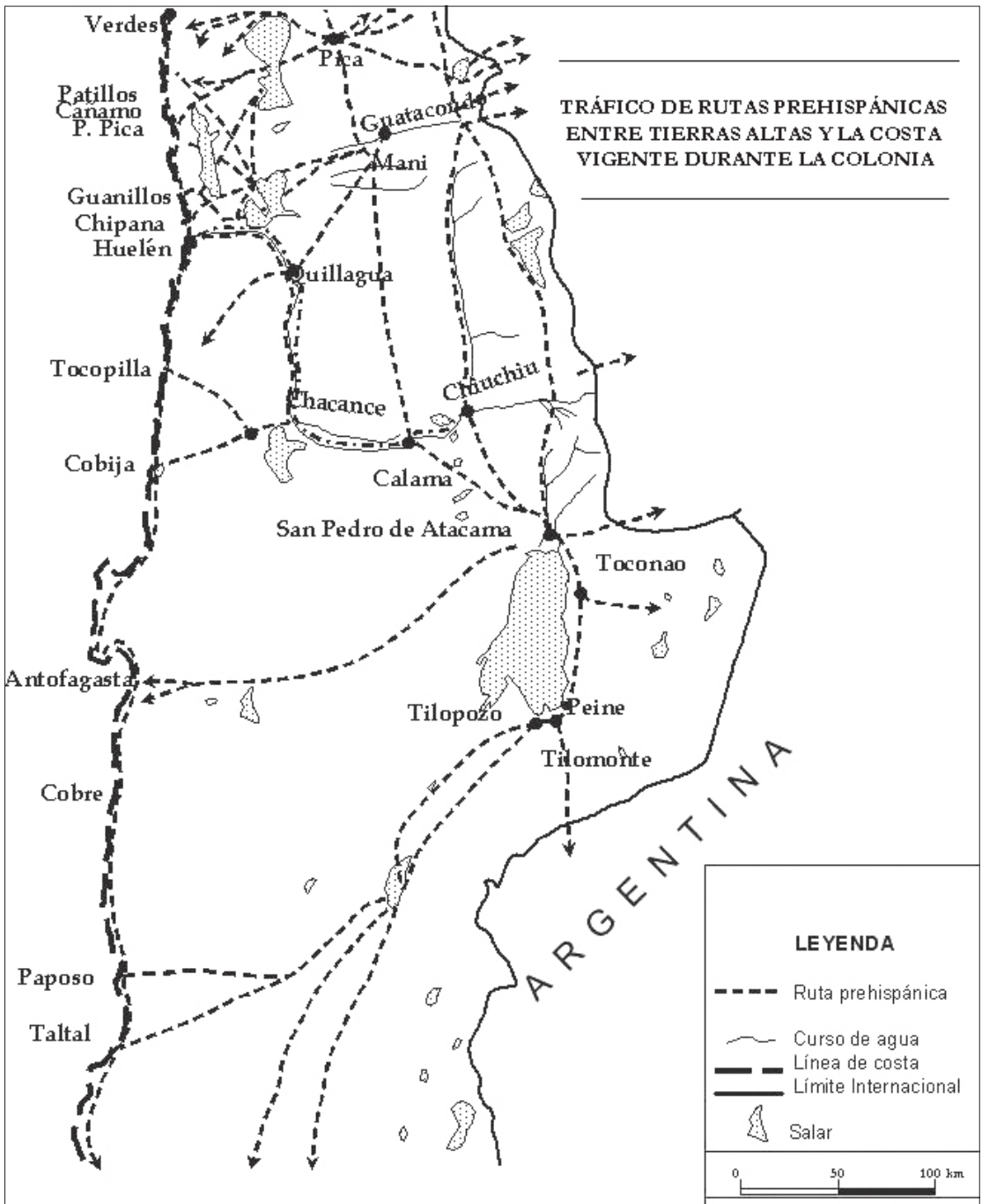

Fuente: Núñez (1984).

El arrieraje argentino, cada vez más creciente, impulsó la apertura de la ruta que conectaría a San Pedro de Atacama-Valle de Copiapó y Paposo, principalmente por la atracción minera del área Calera-Chañaral (Conti, 1993; 2006).

El gobierno de Bolivia decidió hacia mediados de la década de 1860 la construcción de un camino para Cobija, dado el papel importante desempeñado como puerto de salida de las exportaciones agropecuarias del noroeste argentino. En 1863 se supo de la propuesta de Juan Ramón Muñoz Cabrera que no fue viable; nueve años después, la de Aguirre Zavala (Aguirre Zavala, 1871). Hacia fines del decenio se concluyó un servicio postal que empleó los caminos conocidos, para conectar a Salta con Calama y desde ahí hacia Cobija, conformando dos correos mensuales de a caballo.

Los descubrimientos de salitre y plata entre los años 1857-1870 modificaron la vi- 
sión de la conectividad existente. Los servicios de carretas desde Antofagasta (fundada oficialmente en 1868) hacia la Pampa Central se hicieron frecuentes. Los núcleos marítimos de Tocopilla, Mejillones, Cobija y Antofagasta fueron nodos de complejos caminos, senderos y huellas que se diseminaron por entremedio de las quebradas hacia los nuevos yacimientos mineros. Se sabe que el mineral de Naguayán estaba unido en 1870 con Mejillones por un buen "camino carretero". En 1857 los hermanos Domingo y Francisco Latrille organizaron la más numerosa expedición de la época, abriendo la senda costera que atravesó Chacaya, MejiIlones, La Chimba, se internó por la quebrada del Salar del Carmen hasta Ilegar al Cerro del Plomo, descubriendo el salitre en la región de Antofagasta.

La atracción ejercida por los nuevos recursos minerales en explotación fomentó la creación de las llamadas caravanas de cateo, que abrían huellas en pos del reconocimiento de nuevos yacimientos y vetas. Una de estas, dirigida por Díaz Gana, descubrió el mineral de plata de Caracoles en 1870. La noticia estimuló un tráfico inusitado en las 63 leguas que separaba a Cobija de Caracoles, atravesando Culupo, Miscanti y Calama.

Determinados hombres públicos nacionales, como José Victorino Lastarria (Lastarria, 1871) o Aurelio Lastarria (Lastarria, 1880), confiaron que el mineral de Caracoles irradiara una nueva sociedad en el desierto de Atacama, en la visión de José Victorino, bajo el lema de Comte, "Orden y Progreso", mientras que Aurelio fijó su atención en las vías de comunicación ligadas a la industria salitrera y argentífera.

Los nuevos minerales incrementaron el mayor uso de las carretas. José Santos Ossa trajo las primeras para sus negocios bajo la razón social de "Sociedad Exploradora del Desierto de Atacama". Para mediados de la década de 1870 se armaron las carretas denominadas "de huella", que podían soportar grandes pesos de mercaderías y de pasajeros, originando en la ciudad de Antofagasta en 1874 la primera "Empresa de Carretas de Antofagasta", una sociedad germano-chilena.
Durante la guerra del Pacífico, Antofagasta fue el eje para varios caminos tanto para el sur como para el norte e interior del desierto. Un camino carretero se dirigía al norte pasando por Mejillones del sur y termina en Punta Tames, para proseguir "como senda de acémilas hasta el puerto de Iquique" (Vidal Gormaz, 1880). Otro camino se orienta hacia el interior con destino el mineral de Caracoles; otro trasmonta la quebrada del Agua de la Negra y se dirige al calichal de Aguas Blancas, pasa por la quebrada de Mateo y se bifurca: un ramal sigue hacia Aguas Blancas y el otro va por la misma quebrada de Mateo hasta llegar a la de Remienda. De ahí, una senda de mulas existe hasta la caleta Blanco Encalada.

La importancia de Mejillones y su nexo con Antofagasta quedó reflejada en los tres caminos que lo unieron con el Morro, que el ingeniero André Bresson (Bresson, 1997), describió en la segunda mitad del siglo XIX. Uno de ellos era un sendero estrecho y escarpado que nacía cerca del pueblo; otro, que delataba mayor antigüedad, por estar casi hecho, era empleado por los carretones; y el tercero, calificado de grande y beIlo, se localizaba al oeste del Morro de Moreno.

El desarrollo de la industria salitrera en la depresión intermedia entre 1880 a 1934, cuando se cierra el ciclo histórico del modelo Shanks en el desierto de Atacama, tradujo una modificación sensible en las vías terrestres (González Pizarro, 2003; Bermúdez Miral, 1966).

A la espontaneidad de los senderos para aproximar distancias en los arenales se pasó a la complejidad de los tendidos ferroviarios. Se exigió un mayor cuidado puesto que el tramado de vías podía fomentar monopolios entre los centros productivos, los recursos hídricos y los ferrocarriles, como se estaba observando en la región de Tarapacá (Sagredo, 2001).

El explosivo desarrollo de la industria del nitrato de sodio transformó el despoblado. Decenas de oficinas salitreras fomentaron la inmigración de mano de obra y la eficiencia de la conectividad con los puer- 
tos. Los cantones salitreros se cubrieron de caminos: el cantón del Toco, que agrupaba las oficinas próximas al puerto de TocopiIla; el cantón Central que reunía las usinas calicheras entre los pueblos de Baquedano y Sierra Gorda; el cantón de Aguas Blancas que junto con el Central o Cantón boliviano, sacaba su producción por el puerto de Antofagasta y, finalmente, el cantón de Taltal, vinculado al puerto homónimo, contaron con una red tanto de huellas para carretas como de caminos, que los comunicaba con otras oficinas de la misma empresa salitrera.

La anotada relación constituyó una doble inflexión en la pampa calichera, constituyendo un condicionamiento histórico todavía vigente: todo poblamiento fue precedido por las huellas de los cateadores o baqueanos, después por los senderos/caminos que conectaban los mantos de caliche con las usinas. Esta fue la primera inflexión. Todo cambio en los precios de las transacciones, cotizaciones, saturación de mercados o más dramáticamente la baja ley de los nitratos, se tradujo en la paralización de la explotación y el cierre de la oficina salitrera y sus efectos derivados: el despueble de las faenas, el desmantelamiento de los campamentos y centros de elaboración y la soledad sobre las marcas de las ruedas de carretas y camiones. Fue la segunda inflexión.

De esta manera, la discontinuidad espacial derivada de la existencia de escasos nodos urbanos, al interior Calama-Chuquicamata y en la costa Antofagasta, Tocopilla, Taltal, Mejillones, significó -y ha significado- el uso o desuso de caminos en consonancia con los cambios en la industria y en la demografía del hinterland. La crisis de la industria salitrera produjo la desarticulación de caminos secundarios o sufragáneos de los principales, dejando a la vista las marcas del tránsito de vehículos que esporádicamente se internan hacia los denominados "pueblos fantasmas".

La mayor preponderancia del Estado significó una contribución a la red vial regional. La Ley $\mathrm{N}^{\circ} 2.878$ del 8 de febrero de 1914 aportó los fondos imprescindibles para la reparación general de los caminos de la provincia. A esto se agregó la habilitación del puesto público del denominado ingeniero civil de la provincia que vino a mejorar, a partir de la segunda década del siglo $X X$, las posibilidades de estudio, aprobación y fiscalización de los materiales de construcción de las nuevas rutas. Desde mediados de la década de 1910, el funcionamiento del mineral de cobre de Chuquicamata exigió la adecuación de las vías para la introducción de la mecanización y el uso intensivo de vehículos pesados motorizados. Lo mismo aconteció diez años después en las faenas salitreras. Era el símbolo del modelo Guggenheim que se imponía en la minería cuprífera y salitrera.

Lo observado en el hinterland también se repitió en la capital provincial con el arribo de los nuevos automóviles y omnibuses hacia 1916. El adoquinado del casco histórico de la urbe cedió paso gradualmente a una mayor anchura de los trazados de sus arterias y al reemplazo del material por el asfalto.

La Ley de Caminos del 5 de marzo de 1920 determinó una clasificación de las vías en tres órdenes: caminos de primera, segunda y tercera categoría, de acuerdo con los materiales empleados y a la importancia que implicaba la unión entre localidades de mayor significación que otras.

Si se observa la distribución de los caminos de primer orden hallamos que en el departamento de Tocopilla existía una ruta entre su capital y el pueblo del Toco, surgido en 1906, con sus 60 km; la que unía a QuiIlagua con Sierra Gorda a través del Toco y Chacance, con una longitud de 157 km. En el departamento de Antofagasta se localizaban cuatro caminos, el de Antofagasta a Bolivia por Ollagüe, con $460 \mathrm{~km}$; de Antofagasta a Mejillones por la costa, con $62 \mathrm{~km}$; de Antofagasta a Coloso, poblado surgido al sur de Antofagasta hacia 1906, con 14 km; de Aguas Blancas a Santa Catalina, con $120 \mathrm{~km}$. En el departamento del Loa se tenía el camino de Calama a Chuquicamata con una extensión de $20 \mathrm{~km}$; el departamento de Taltal contaba con cuatro caminos, evidenciando todavía la fortaleza de su industria minera: el de Taltal a Santa Catalina, con 114 km; el de Taltal a Estación "Altamira", 
sección Brea a Altamira, que se extendía por 80 km; el de Estación "Altamira" a Santa Catalina con $75 \mathrm{~km}$, y por último, el de Santa Luisa a Estación Agua Verde, con 30 km (Valenzuela, 1926).

El total de kilometraje que evidenciaba la provincia era de $2.978 \mathrm{~km}$, distribuidos en $1.313 \mathrm{~km}$ de caminos de primer orden, $350 \mathrm{~km}$ de segundo orden y 1.315 de tercer orden, haciéndose notar que existían carreteras dignas de mención, como la que unía Calama-Chiuchiu; Tocopilla-Cobija con el Toco; Blanco Encalada, Paposo y Taltal y Cachinal y otras que eran meras sendas o rutas troperas que no merecían la calificación de carreteras (INTER-AMERICA, 1924).

Este nuevo panorama de modernización que exhibía la región se proyectó hacia otras obras de infraestructura vial. Prueba de ello fue la publicación por la Dirección General de OO.PP, Inspección de Caminos y Puertos del Boletín de Caminos, a partir de 1927, continuada desde 1930 por la Revista de Caminos. Otra expresión fue la dictación de la Ley de Caminos No 4.851 del 10 de marzo de 1930, que clasificó los caminos en públicos y privados, reglamentando solamente los primeros y dividiéndolos en internacionales, nacionales y regionales; en los nacionales distinguió dos categorías, los que unían entre sí a las capitales de provincias y las vías fluviales y los que comunicaban a los primeros con los puertos de navegación. Según donde estuviesen localizados en urbanos y rurales y respecto a la naturaleza de los materiales, en pavimento superior, estabilizados y ripiados y de tierra. En cuanto al ancho de la calzada los dividía en carreteros y troperos y en lo que concernía al tránsito en permanente y de temporada.

Las vías principales que conectaban a las capitales departamentales -Tocopilla, Calama, Taltal- calificaron como estabilizadas, no faltando sectores de tierra y reuniendo el mayor kilometraje.

La crisis económica mundial que coincidió con la crisis salitrera regional en el bienio 1930-1931 Ilevó a plantearse el uso de la tracción animal para ahorrar combustible. Empero, la realidad del empleo de la trac- ción mecánica en las actividades mineras definió la situación, suscitada por la eventualidad planteada por un decreto del Ministerio del Interior de 22 de abril de 1932 (González Pizarro, 1999).

Los efectos de la crisis fueron a veces paradójicos: mientras se ampliaba el parque automotriz de Antofagasta, en 1932 se cerró el puerto de Coloso, que generó una caída del tráfico de carga, mas no el de pasajeros en esa ruta costera. Hacia mediados de la década de 1930, superadas las secuelas de la crisis, se observó un renovado uso del camino de Huaytiquina a Calama como tramo internacional con destino hacia Argentina. En el mismo periodo adquirió relevancia como eje caminero el pueblo de Pampa Unión, creado en 1911, pues se transformó como indicador del tráfico y uso del camino principal de Antofagasta hacia la pampa salitrera. Un informe del año 1934 refiere de un tráfico diario de 72 vehículos, donde un 64\% era de vehículos de carga; le seguía el trayecto Antofagasta-Tocopilla con 63 vehículos, pero el $77 \%$ era de vehículos de pasajeros. Incluso el eje Calama-San Pedro de Atacama-Toconao mostraba un 60\% del tráfico de vehículos de carga (A.I.A, 1934a: 147).

La fundación del pueblo de Baquedano en junio de 1926 proveyó al Ministerio de Fomento, del que dependía todo lo relativo a obras públicas, de un nodo que tendría crucial significación -informaba el ingeniero de la provincia en oficios de junio y julio de 1926- para el tramado de los ferrocarriles y también para la medición de la frecuencia vehicular, al ir perdiendo importancia Pampa Unión (A.I.A, 1926: 46).

Se debe resaltar que el Departamento de Caminos de la Dirección General de Obras Públicas contaba con variados puntos de observación de la red caminera de la zona, en base a los campamentos permanentes de cuadrillas de servicios de camino diseminados en las diversas rutas de la provincia. Dentro de sus observaciones no hubo registros del uso de las vías mencionadas por vehículos de tracción animal.

Las rutas principales se mantenían en buen estado y las secundarias mostraban 
condiciones regulares, principalmente en las conexiones entre localidades muy pequeñas, como ser Varillas a Paposo, Rica Aventura a Hilaricos, Rica Aventura-QuiIlagua, o María Elena-El Toco, incluso Pampa Unión-Sierra Gorda, que arrojaba una cuarta parte de las rutas secundarias en malas condiciones. Los que unían a San Pedro de Atacama- Toconao o el camino del lago Ilimae a Alto Inca, eran calificados como malos.

El interés mayor en las obras públicas era dejar en óptimas condiciones la red caminera que unía a los centros productores con los puertos de embarques. Y en ello coincidían los intereses de los empresarios salitreros, los comerciantes de Antofagasta y Tocopilla y las autoridades departamentales y de la provincia.

Durante el segundo gobierno de Alessandri Palma hubo modificaciones a la Ley de Caminos, reforzando el papel estatal en afianzar la red de vías asfaltadas. Consignemos que una última reforma en tal sentido se recogió en el DFL 206 del Ministerio de Hacienda del 5 de abril de 1960 que en lo grueso, conservó la clasificación de caminos establecida en 1930.

La normativa concerniente a la anchura de los caminos públicos obligó a la Municipalidad de Calama, a partir de 1943, a convenir con la Chile Exploration Co., la empresa dueña del mineral de Chuquicamata, una acción mancomunada, donde también se involucró la Dirección de Pavimentación, para mejorar la ruta existente entre Calama y Chuquicamata. En 1951 se dio inicio a la construcción de un nuevo camino. La gradual transformación de Calama en ciudad dormitorio de Chuquicamata también ayudó a la incorporación del asfalto en sus calles principales, desde mediados de la década de 1940.

El crecimiento de la red caminera hacia fines de la década de 1950 había alcanzado $\operatorname{los} 3.500 \mathrm{~km}$, distribuidos en $688 \mathrm{~km}$ asfaltados, $1.528 \mathrm{~km}$ ripiados o estabilizados y $1.274 \mathrm{~km}$ de suelo natural. Del total, un $20 \%$ requería mínima conservación, un $40 \%$ una conservación permanente, un $10 \%$ una en forma periódica y un 30\% quedaba materialmente exento de toda atención (Bull, 1957).

En la década de 1960 se construyó la Carretera Panamericana, convirtiéndose en el eje de estructura caminera de la provincia. A ella se conectó en 1961 el mineral de Mantos Blancos a través de la vía caminera que une Baquedano con Antofagasta.

El panorama de la red caminera basada en la comunicación del hinterland con los puertos forjó una red territorial tipificada de tipo de estructura espinal y semidendrítica, dado que su expansión fue a partir de la existencia de recursos minerales en áreas del interior y de desvío desde el camino longitudinal hacia otros lugares (Muñiz Solari, 1985).

La calificación de los caminos internacionales, nacionales y regionales permitió sopesar la importancia de la ruta del paso de Huaytiquina, y más tarde, de Jama para unir las localidades chilenas con las argentinas del noroeste. En la década de 1920 un pionero, Oscar Orchard, unió con su automóvil el trayecto entre AntofagastaSalta. Su proeza fomentó el uso de la ruta por Huaytiquina que hacia 1947 era ya un camino consolidado (El Abecé, 1947). La otra opción, dependiendo de las condiciones climáticas, fue Jama. Una alternativa fue la senda de Zapaleri que, desde antaño, había sido aprovechada por los arrieros argentinos.

El paso de Jama en la actualidad convertida en el camino principal que une a ambas naciones vio transitar la primera caravana de automóviles argentinos, en septiembre de 1967, desde Jujuy hacia Calama (Cabezas, 1999).

\section{La actividad costera: caletas, muelles y puertos}

Las caletas de los indios changos dieron muestras del conocimiento intuitivo que sobre las bahías abrigadas mostraron los pueblos marítimos del norte; fueron bahías protectoras de los vientos y benefactoras de recursos del mar. Posibilitaron la transformación de los elementos de la fauna marina en 
utensilios para el hombre -el arpón, las pieles de lobo marino- y dieron cuenta de la técnica arcaica de la pesca y de la embarcación, cuyo mejor testimonio fue la construcción de la balsa de cuero del mamífero acuático (Núñez, 1979; Bittman, 1977). La existencia de excedentes en pescados y mariscos les permitió a los changos hacer trueque con los pueblos del interior, fundamento de las rutas transversales de la costa-interior. El viajero francés Alcides D’Orbigny las observó en 1830 (D'Orbigny y Ballesteros, 1958).

Los hispanos al tener noticias de tales caletas los llevó a emplazar los primeros asientos portuarios, como Santa María Magdalena de Cobija en tiempos coloniales, más tarde rebautizada como Puerto Lamar, al norte del trópico de Capricornio, y Paposo hacia los límites meridionales del desierto de Atacama.

Cobija albergó a la comunidad de changos y como tal mereció una atención eclesial; hacia fines del siglo XVIII se alzó como un eje importante de las comunicaciones hacia Copiapó, teniendo una vinculación marítima con Coquimbo, de modo irregular, como también hacia San Pedro de Atacama (Bittman, 1980). Cobija fue declarado puerto menor en 1865 .

Antes del surgimiento de Antofagasta, Cobija fue el puerto principal de Bolivia de todo género de mercaderías con destino a las ciudades de Potosí, Chuquisaca, Tupiza (Vidal Gormaz, 1884).

Fue en el transcurso del siglo XIX cuando emergieron los principales puertos que se mantienen hasta hoy. En la década de 1840 se hizo el reconocimiento de las guaneras de Mejillones. Mejillones en octubre de 1857 era elevado a puerto menor. A mediados de 1860 comenzó a poblarse de modo sistemático. Fue fundado oficialmente por Bolivia el 25 de enero de 1867.

Después de la guerra del Pacífico, MejiIlones fue perdiendo tanto el potencial de su riqueza guanera como de la importancia como puerto: en agosto de 1888 dejó de ser puerto menor. Sujeto a los vaivenes económicos, fue refundado en 1906, contando con una nueva planta de su población y con el establecimiento de las maestranzas del Ferrocarril de Antofagasta a Bolivia (F.C.A.B.). En la década de 1920 contaba con ocho muelles: $N^{0} 1$ y 8 de la empresa Gibbs \& Co.; $\mathrm{N}^{\circ} 3$ de The Pacific Steam Navigation Co.; $\mathrm{N}^{\circ} 4$ y 5 del F.C.A.B; $\mathrm{N}^{\circ} 6$ y 7 de la empresa Buchanan Jones \& Co (Swett, 1924).

Al despuntar el siglo $\mathrm{XX}$, antiguas caletas diseminadas a lo largo de la costa de la provincia proseguían con sus actividades, a veces ligadas a las faenas portuarias modernas, otras preservando usos de tecnologías de antaño o manteniendo la sobrevivencia de reductos de changos, como eran:

A 25 millas al sur de la desembocadura del río Loa se situaba la caleta Paquica o San Francisco; al sur de Tocopilla estaba la caleta Guanillos o también Ilamada Guanillo del Sur; a cuatro millas de esta localidad se hallaba Gatico; entre Cobija y Mejillones se localizaban las caletas de Tames, Michilla y Gualaguala; a ocho miIlas al sur de Mejillones se encontraba Herradura de Mejillones o de Choros; al sur de esta y a ocho millas las caletas Bandurria, Errázuriz y un poco más al sur la caleta Constitución.

La bahía Moreno o de San Jorge resguardaba las caletas de Barranca, Abato, Chimba. La caleta Bolfin estaba a una y media milla al norte de Morro Jara. Y aproximadamente, a veinte millas al sur de este promontorio, se encontraban las caletas Agua Dulce y Agua Salada. A seis millas de esta última se encontraba el puerto de Cobre y a ocho millas al sur la caleta Blanco Encalada o Remiendo. La caleta Botija se localizaba a nueve millas al sur. Cuatro millas con dirección sur de Botija la caleta Colorada, que poseía atracadero para lanchas y botes, y más al sur, a seis millas de la Punta Panul, se levantaba el poblado de Paposo. En la bahía de Nuestra Señora, además de Taltal, se localizaban las caletas de Oliva o Cascabeles y Hueso Parado. Cifuncho fue la última caleta de la provincia, al sur de Taltal (Espinoza, 1903).

Es importante indicar que Mejillones pudo conciliar tanto los intereses británicos 
de The Antofagasta (Chili) and Bolivia Railway Company Limited, que emplazó su maestranza como del Estado chileno para dar una solución a las dificultades por las que atravesaba Antofagasta.

Expresivo fue el informe del ingeniero Emilio de Vidts, encargado por el Gobierno y la Armada para tal propósito:

"La idea de abrir nuevamente el puerto de Mejillones ha sido indicada muchas veces desde el abandono de este puerto, i lo que ha determinado su realización, ha sido la situación aflictiva porque ha atravesado el puerto de Antofagasta en estos últimos tiempos. En efecto, la situación desesperada del comercio de Antofagasta es tan conocida de las autoridades como del público... El puerto de Antofagasta por sus pocas comodidades tanto naturales como artificiales, no puede hoy día dar abasto al enorme incremento que ha tomado, i hoy día el rendimiento de sus instalaciones ha llegado al máximum, necesitándose en consecuencia ensanchar estas instalaciones de una manera rápida" (De Vidts, 1906: 8).

Tocopilla evolucionó desde caleta de pescadores de changos, denominada Bahía Algodonales en el siglo XVII, hacia un puerto que fue consolidándose en 1843 al ritmo de las faenas mineras y de la explotación del guano; se vio afectado en 1877 por un terremoto y maremoto al igual que Cobija.

En 1909 la significativa producción salitrera del cantón del Toco, cuya salida era Tocopilla, coadyuvó a la construcción de un muelle de atraque para embarcaciones mayores (Rossi, 1993). Cuatro años después, The Chile Exploration Co., instaló su planta eléctrica, reforzando su importancia para el hinterland cuprero.

A mediados de 1920 Tocopilla exhibía un conjunto de muelles de cierta importancia: Phoenix Mining de la Cía. Minera de Tocopilla; los muelles 1, 2 y 3 de la Anglo Chilean Railways Co., y Bellavista Norte y Sur de la Cía. Salitrera Tocopilla.

El gobierno de Ibáñez, por medio de la Ley $N^{\circ} 4.525$, del 7 de enero de 1929, le su- ministró un fuerte impulso por medio del mejoramiento de su puerto.

Taltal se integró como puerto en 1852 y su significación fue ser la única salida de exportación de la producción salitrera del cantón de Aguas Blancas.

Antofagasta fue poblada por Juan López en 1866 y en 1868 fundada de manera oficial, imponiéndose rápidamente como el puerto principal de la zona del desierto (Arce, 1930; Bermúdez, 1966; González Pizarro, 1980, Benavides et al., 1994).

Antofagasta desplegó su actividad portuaria por medio de muelles particulares y privados, los cuales funcionaron hasta bien entrado el siglo XX por medio de lanchones, los denominados "lanchones maulinos", que posibilitaron el embarque y desembarque de pasajeros y mercaderías, dado que los muelles estaban emplazados en la Poza o dársena, que medía quinientos metros de norte a sur y 350 metros de este a oeste, con un fondo variable entre tres y seis metros, lo que impedía el acceso a barcos cuyo calado fuera superior a tres metros y medio (Vidal Gormaz, 1881).

Los muelles estuvieron conectados con las instalaciones industriales salitreras.

El primer muelle de Antofagasta se construyó en 1875, teniendo un largo de ciento treinta y siete metros y un ancho de diez a catorce, y una altura cercana a los dos metros sobre la alta marea. Sirvió a las operaciones militares del conflicto de 1879-1883 y fue reparado en 1890 .

En el curso de los acontecimientos bélicos fueron levantados otros muelles. El Miraflores se construyó producto de la concesión hecha a Rafael Barazarte en 1881 y que todavía permanece en la antigua Poza. Su extensión es de $172 \mathrm{~m}$ por $13 \mathrm{~m}$ de ancho. A fines de 1882 se construyó el muelle de Bellavista, vinculado a la Compañía Beneficiadora de Metales, y más tarde adquirido por la Compañía de Ferrocarriles, que le hizo modificaciones alcanzando una extensión de $150 \mathrm{~m}$. A fines del siglo XIX esta última empresa acometió la construcción de un malecón de ciento quince metros. 
The Lautaro Nitrate Co. obtuvo la autorización de contar con su muelle en 1913 y construyó uno de $60 \mathrm{~m}$ de largo por $8 \mathrm{~m}$ de ancho. Este se vino a unir a otro construido tres años antes por The Pacific Steam Navigation Co., de $115 \mathrm{~m}$ de largo por $14 \mathrm{~m}$ de ancho.

En 1921 la empresa West Indian Oil Co. levantó el muelle El Cobre, de $64 \mathrm{~m}$ de largo por $4 \mathrm{~m}$ de ancho.

A mediados del decenio de 1920 el panorama de los muelles en pleno renacer de la industria del salitre era de cambios de dueños y construcción de otros: Ilabaca de la firma Ilabaca, Espinoza \& Co., Salitre de la Cía. Salitre de Antofagasta, Bellavista y Ferrocarril del F.C.A.B., Lewis de la firma Lewis \& Co., Miraflores de The Nitrate Agencies, Barnett de la firma Barnett \& Co., y Yungay de la Sociedad Marítima Muelle Yungay.

Hacia 1934 los muelles todavía presentaban un relativo estado de conservación y las concesiones de los muelles P.S.N.C, Miraflores y El Cobre estaban próximas a caducar, detallaba la memoria de la Gobernación Marítima de Antofagasta.

Hemos visto que la refundación del puerto de Mejillones fue una respuesta parcial al colapso de la actividad marítima de Antofagasta. En sesión extraordinaria de la Cámara de Diputados, del 21 de enero de 1904, se denunció que los "malecones se han ido destruyendo sin hacerse el menor trabajo que hubiera impedido la pérdida total de las gruesas sumas que ahí se han gastado" (Cámara de Diputados, 1903).

La implementación del puerto de Coloso tampoco fue una solución. Coloso contó con un malecón inicial de treinta metros y más tarde de treinta y cinco metros, que el Gobierno autorizó a la empresa Matías Granja el 25 de septiembre de 1902, y posteriormente en agosto de 1904 y junio de 1906. Fue un malecón que estuvo destinado a la producción salitrera de Aguas Blancas. La sucesión de Matías Granja enajenó en octubre de 1908 el ferrocarril y el puerto de Coloso a W.R.Grace y Cía (Sociedad Anónima, 1930).
La densidad del tráfico de exportaciones de nitrato en todos los puertos de la provincia obligó al Gobierno a fijar un plan general de mejoramiento que se encargó a la Comisión de Puertos, vía Ley $N^{\circ} 2.390$ del 7 de septiembre de 1910. Los puertos de Tocopilla, Antofagasta, Taltal y Mejillones fueron incorporados a dicho plan.

El informe de la Comisión de 1913 fue clave en la decisión del Gobierno de construir un puerto artificial en Antofagasta en 1916. Era el segundo en importancia después de Valparaíso; pero si se consideraba a Mejillones y Coloso, Antofagasta quedaba en primer lugar, seguido de Iquique, Pisagua, Taltal, Tocopilla y Valparaíso.

En la acción gubernativa pesó la riqueza minera y la conectividad existente, incluido el ferrocarril internacional a Bolivia y, por cierto, los tipos de naves que recalaban en Antofagasta: buques a vapor para el comercio exterior, buques a vapor para el comercio de cabotaje, veleros del comercio exterior y veleros del cabotaje (Claro Solar et al., 1913).

La construcción del puerto, iniciada en junio de 1920, encontró dificultades en cuanto a las canteras para las obras de atraque, que se concluyeron en 1927, y fue inaugurada por lbáñez del Campo a fines de 1928. Una de sus piezas principales fue la construcción de la gigantesca grúa Titán por la empresa Baburizza Lagarrigue y Cía (Reyes, 1928), para el traslado de los bloques, y que hoy se puede admirar en el parque de acceso al puerto de Antofagasta.

El puerto artificial, conocido como el Molo Fiscal, contó con una superficie de $30.000 \mathrm{~m}^{3}$ de aguas abrigadas y 40.000 $\mathrm{m}^{2}$ de terrenos para atender simultáneamente nueve navíos (Panadés y González, 1998). En 1932 la empresa Baburizza Lagarrigue y Cía. entregó terminados los Molos del Sur y Occidental; las obras inconclusas del Molo del lado de tierra y la explanada y malecones del Molo Occidental pudieron avanzar por el acuerdo entre el Estado y las empresas constructoras del puerto sobre la forma de pago de las deudas en febrero de 1935. Recién en 
1952 estuvo en operatividad integral todas las instalaciones portuarias.

Se debe acotar que el esplendor de los puertos de la provincia estuvo ligado a la fortaleza de la actividad minera y comercial. Hacia 1911, Gallardo Nieto (1911) hacía notar que una diferencia entre las provincias de Tarapacá y Antofagasta era el número de puertos destinados a la exportación del salitre: Tarapacá tenía cuatro puertos (Iquique, Junín, Pisagua y Caleta Buena) y Antofagasta cinco (Tocopilla, Mejillones, Antofagasta, Coloso y Taltal).

En cuanto al rubro mercantil, este tuvo una importancia en el cabotaje del abastecimiento regular de productos agropecuarios, toda vez que las líneas de navegación internacional hacían recaladas regulares en ellos, viéndose afectado las poblaciones respectivas cuando no contaron con apoyo gubernamental.

Un oficio del gerente de la Compañía Sudamericana de Vapores al director del Litoral del 10 de noviembre de 1934, relaciona claramente el nexo de los puertos-abastecimiento- navíos:

"Si bien es verdad que las oficinas de María Elena y Pedro de Valdivia son servidas por el puerto de Tocopilla, las frutas tropicales que traen nuestros vapores bien pueden ser enviadas por el puerto de Antofagasta... cualquier demora en el transporte de la fruta hace que ésta madure antes de Ilegar, motivo éste que nos obliga a acortar los viajes y sacrificar algunos puertos. Naturalmente que si hubiera algún incentivo (en materia de alza de las tarifas) para una escalada a Tocopilla, se podría estudiar" (A.I.A., 1934b).

La importancia de los puertos de la provincia de Antofagasta se vio reflejada en la designación de "Prácticos de $1^{\circ}$ Clase" para Tocopilla, Mejillones, Antofagasta, Coloso y Taltal, según disponía el reglamento de la Ley de Cabotaje del 4 de agosto de 1922.

La jerarquía de los puertos hacia 1926 también guardó relación con la cantidad de buques que fueron servidos en ellos. Antofa- gasta recibió 1.640 naves; Taltal, 931; Tocopilla, 718; Mejillones, 382, Gatico, 178 y Coloso, 45 (Inter-América, 1924).

Sin embargo, estos guarismos positivos comenzaron a declinar después de 1930, siendo este año el del cenit en el flujo de pasajeros embarcados en todo el periodo que se extiende hasta 1960 (Cuadro $N^{\circ} 1$ ):

Cuadro $\mathrm{N}^{\circ} 1$

FLUJO DE PASAJEROS EMBARCADOS

\begin{tabular}{|lrrrr|}
\hline & Año 1930 & 1940 & 1950 & 1960 \\
\hline Tocopilla & 6.917 & 1.464 & 199 & 20 \\
Antofagasta & 14.515 & 7.129 & 5.178 & 1.895 \\
Taltal & 2.853 & 770 & 24 & 0 \\
\hline
\end{tabular}

Fuente: Miranda (1962).

Coincidente con esta importancia de los puertos del desierto de Atacama existió mayor concurrencia de compañías de navegación tanto extranjera como nacional, como lo evidenció Antofagasta.

Entre las empresas chilenas figuraban la Compañía Sudamericana de Vapores, C.S.A.V., pionera desde el siglo XIX, que mantuvo un servicio regular desde el sur los días lunes y desde el norte los días jueves, transportando carga y pasajeros. R.W. James y Compañía hacía un recorrido quincenal cubriendo entre Valparaíso e Iquique. La Sociedad Anónima Marítima Chilena poseía un servicio fijo semanal desde el sur y desde el norte, dedicándose al transporte de pasajeros. La Sociedad Comercial Braun y Blanchard aportaba un servicio semanal de transporte de pasajeros. La Sociedad Anónima Torres, la Ward. Ltda., la Compañía de Navegación Interoceánica, la de Martínez, Pereira y Cía. Ltda., la Sociedad Industrial de Aysén y los Armadores Latorre y Troncoso, hicieron un servicio irregular que variaba de quince a treinta días transportando carga y pasajeros.

Otras compañías de vapores fueron Artigas Riofrío y Co., Bohórquez y Cía., O. Pinto y Cía., Compañía Nacional de Vapores, 
Alb-Haverbec y Cattavara \& Aguirre. La línea de vapores de González, Soffia y Cía. se destacó en la compra y distribución de frutos del país y harina con destino hacia las oficinas salitreras.

Entre las empresas internacionales sobresalían The Pacific Steam Navigation Company, con un servicio regular en Antofagasta y Mejillones. Grace Line laboraba con dos líneas de vapores y recalaba cada quince días en Antofagasta con pasajeros y carga. La Compañía de Navegación Italia (Societá Nazionale di Navigazione, de Génova) con un servicio regular mensual, mientras las Compañías de Navegación Alemanas (Cosmos) tenían dos líneas de navegación que Ilegaban mensualmente a Antofagasta, con pasajeros y carga. La Compañía Real Holandesa de Vapores (Royal Netherlands West India Mail) y la Compañía Francesa de Navegación (Compagnie Générale Transatlantique), así como la Compañía Japonesa de Navegación (La Toyo Kisen Kaisha) cubrían con un servicio irregular tanto el transporte de pasajeros como el embarque de producción de minerales. Esta compañía abrió en 1906 la ruta entre Iquique y los puertos asiáticos, y fomentó la inmigración china en el Norte Grande.

Después de la Segunda Guerra Mundial, el friso portuario de la provincia cambió por la desaparición de las grandes compañías navieras europeas.

\section{Tecnificando el suelo árido. La red ferroviaria}

Cuatro años más tarde de ser fundada Antofagasta, se estableció en octubre de 1872 la Compañía de Salitres y Ferrocarril de Antofagasta. A fines de ese año, inició la construcción de la vía férrea hacia el Salar del Carmen. Con ella comenzaba una vasta y compleja relación entre la industria salitrera y los ferrocarriles.

En efecto, la concesión de los señores Wattson y Meiggs por el gobierno de Bolivia en julio de 1872, después de fracasar otra propuesta de mayo de 1871, no avanzó mucho, y en julio de 1877 la administración de La Paz rescindió el contrato. Otra idea en
1877 desde Mejillones no prosperó por el desastre natural del 9 de mayo del mismo año (Arce, 1930).

El material acopiado fue utilizado para establecer el Ferrocarril Urbano de Antofagasta, del cual Eleazar Miranda fue su principal promotor en 1893. El Ferrocarril Urbano de Antofagasta constituyó un gran aporte a la movilización citadina, pues entre 1901 y 1907 transportó desde medio millón a un millón trescientos cuarenta y seis mil pasajeros. Fue un tranvía de tracción animal. Nunca fue electrificado y dejó de funcionar en $1914^{3}$.

Con el fin de las operaciones bélicas en 1884 y la posición de Chile como soberano del desierto de Atacama, se asistió a una verdadera agitación por parte de particulares por solicitar concesiones al gobierno para la construcción de líneas ferroviarias con la finalidad de unir las oficinas salitreras y otras labores mineras con los puertos de la provincia de Antofagasta.

Si se examinan las sesiones de la Cámara de Diputados encontraremos que los años 1884, 1887, 1893, 1895 y 1899, por citar algunos, exhibieron la efervescencia consignada 4 .

3 Allen Morrison ha puntualizado que, después de la Primera Guerra Mundial, "Antofagasta fue la más grande ciudad chilena sin tranvías y la ciudad que nunca tuvo un tranvía eléctrico, (pero) es la única ciudad chilena que ha preservado conscientemente un tranvía" (Morrison, 1992).

4 S.E. del 7 de enero de 1884 para la construcción del FF.CC. de Antofagasta hacia Aguas Blancas; S.O. del 27 de diciembre de 1887 el proyecto de FF.CC. entre Pampa Alta y San Pedro de Atacama, sin perjuicio de la concesión hecha en enero de 1884 a la Cía. de Salitres y Ferrocarriles de Antofagasta; S.E. del 16 de agosto de 1889 solicitud de J. Phillips para construir un FF.CC. a vapor entre Antofagasta y Aguas Blancas; S.E. del 16 de octubre de 1893 autorización a Carlos A. Watters de construir una línea férrea tomando como punto de partida el kilómetro 20 del actual FF.CC. de Antofagasta a Bolivia; S.O. del 4 de junio de 1895 para construir un FF.CC. del Toco a Tocopilla; S.O. del 1 de septiembre de de 1897 concede autorización a José Antonio Moreno para construir y explotar un FF.CC. que una el puerto de Paposo con el mineral del Desierto; S.O. del 31 de agosto de 1899 donde se examina la solicitud de Enrique Barra para construir un FF.CC. de vapor desde el mineral de Chu- 
En enero de 1890 el Presidente Balmaceda autorizó a dos empresas para construir líneas ferroviarias en la provincia de Antofagasta. Las arduas discusiones parlamentarias mostraron nítidamente la compleja relación entre los negocios y la política ${ }^{5}$ y, también, los intereses del Estado por la seguridad nacional $^{6}$. De igual modo, los intereses entre particulares por ampliar sus concesiones, donde empresarios nacionales, como Daniel Oliva por construir un ferrocarril entre su

quicamata hasta la línea del FF.CC. de Antofagasta a Bolivia, en un punto situado entre los kilómetros 250 a 260 de la expresada línea; S.O. del 9 de diciembre de 1899 se concede a Enrique Barra y a Norman Walter lo solicitado; S.E. del 21 de noviembre de 1908, se examina solicitud de Eduardo Koegel para construir un FF.CC. de Mejillones a Antofagasta. Cf. Cámara de Diputados. Legislatura Extraordinaria, 1883-1884. Imprenta Nacional, 1884; Cámara de Diputados. Legislatura Ordinaria, 1887. Imprenta Nacional, 1888; Cámara de Diputados. Legislatura Extraordinaria, 1889. Imprenta Nacional, 1889. Cámara de Diputados. Legislatura Extraordinaria, 1892-1893. Imprenta Nacional, 1892. Cámara de Diputados. Legislatura Ordinaria 1895, Imprenta Nacional, 1895; Cámara de Diputados. Legislatura Ordinaria, 1897. Imprenta Nacional, 1897; Cámara de Diputados. Legislatura Ordinaria, 1899. Imprenta Nacional, 1899; Cámara de Diputados. Legislatura Extraordinaria, 1907-1908. Imprenta Nacional, 1907.

5 La conjunción entre las empresas de ferrocarriles y la venta de aguas provocó intereses contrapuestos entre los contratos de las primeras y las autoridades políticas. Principalmente, fue la discrecionalidad en las tarifas cobradas. La concesión de aguadas a la Compañía del Ferrocarril de Taltal la obligó a vender el agua a la población de Taltal a un peso el metro cúbico; empero, la empresa la vendía a principios de 1901 a tres pesos, o las diferencias entre la Compañía de Salitres de Antofagasta y la Empresa de Ferrocarriles de Antofagasta, donde esta última, a juicio del ministro de Industria y Obras Públicas, "no le daba facilidades para el acarreo de sus productos a la costa", según informaba en la Cámara de Diputados, en 15 de junio de 1907 (Cámara de Diputados, 1907). Harold Blakemore (Blakemore, 1996) habla de la política de la empresa de F.C.A.B. de "tener buenos amigos" en el sector político.

6 La Ley $N^{\circ} 2.020$ del 7 de enero de 1884 de los Ferrocarriles del Estado, "como empresa industrial de acarreo y transporte", en cierta forma, respondió a esa inquietud. Cuando el gobierno contrató al ingeniero inglés Josías Harding, el 20 de julio de 1901, para el estudio del Ferrocarril Longitudinal a Tarapacá, el entonces ministro de Industria y Obras Públicas, Fernández Blanco, expuso en la sesión del 25 de julio de 1901 que "la obra en proyecto es de la mayor importancia por razones de seguridad nacional, porque se trata de la conservación de la fuente más abundante de las entradas fiscales" (Cámara de Diputados, 1901). pertenencia "Atacama" y "Refresco" en febrero de 1893 en la zona de Taltal despertó recelos de terceros (Cámara de Diputados, 1982). En este sentido, la producción legal pertinente favoreció a las empresas ya establecidas. La Ley $N^{\circ} 1.437$ del 18 de enero de 1882 autorizó a los señores Juan Basterrica, Juan C. Vera y Francisco Miranda para construir un tren a vapor que una el puerto de Antofagasta con la salitreras de Aguas Blancas. A Rafael Barazarte, por Ley $N^{\circ} 2.802$ del 3 de septiembre de 1886, se le autorizó a construir un ferrocarril de vapor entre Paposo y el mineral del Desierto. En esa misma fecha, la Compañía Minera Arturo Prat y la Empresa del FF.CC. de Taltal es autorizada para construir un ferrocarril entre el puerto y el establecimiento de amalgamación de la Compañía Minera mencionada (Anguita, 1912: II). En agosto de 1887 a esta se le autorizó extender el ferrocarril hasta el mineral de Cachinal. Por Ley $N^{\circ} 3.209$ del 23 de enero de 1888 E. Squire fue autorizado para tender un ferrocarril entre las salitreras del Toco y un puerto de la costa entre el río Loa y el puerto de Cobija (Anguita, 1912: III).

En este entonces el Estado se preocupó por examinar la viabilidad de algunos tendidos ferroviarios entre Caracoles y San Pedro de Atacama.

Hay que destacar que la provincia de Antofagasta vio el despliegue de cuatro hitos de los denominados "caminos de hierro". Uno en torno al fortalecimiento de la Compañía de Salitres y Ferrocarril de Antofagasta, que fue autorizada en enero de 1884 para atravesar todo el cantón salitrero Central o boliviano con la finalidad de conectar su tendido con Bolivia. La iniciativa involucró a la Compañía Huanchaca de Bolivia, que necesitaba sacar su producción minera de Huanchaca por el ferrocarril hacia Antofagasta. El ramal obligó al ingeniero J. Harding a construir sobre el río Loa en Conchi un puente de 240 metros de largo y 100,9 de altura, desde el lecho del río hasta los rieles, siendo uno de los puentes más importantes del mundo (Bermúdez Miral, 1984).

La Compañía Huanchaca se hizo del ferrocarril de la Compañía de Salitres de Antofagasta en 1887, estableciendo en Londres 
The Antofagasta (Chili) and Bolivia Railway Co. Ltd. La Cía. Huanchaca extendió el ferrocarril desde Antofagasta hasta Oruro en 1892, y un ramal desde Uyuni hasta la mina principal de Pulacayo, en noviembre de 1889 (Blakemore, 1996).

El F.C.A.B. amplió sus instalaciones en Mejillones en 1906, constituyendo su maestranza un gran impulso para la vida diaria del refundado puerto (Panadés Vargas, 1995). El ferrocarril que unió a la ciudad de Antofagasta con La Paz, en el marco del
Tratado de Paz y Amistad entre Chile y Bolivia de 1904, se inauguró en 1917.

El tendido ferroviario desde Antofagasta hasta la frontera con Bolivia se tradujo en la implementación de una serie de estaciones con ramales hacia las oficinas salitreras alcanzando una longitud de cuatrocientos treinta y cinco kilómetros hasta Ollagüe.

Si miramos la extensión y el tramado podemos apreciar la gravitación de la empresa del F.C.A.B. (Cuadro No 2).

Cuadro $\mathrm{N}^{\circ} 2$

ESTACIONES DE LA EMPRESA F.C.A.B.

\begin{tabular}{|c|c|c|c|}
\hline $\begin{array}{c}\text { Kilómetros } \\
\text { desde Antofagasta }\end{array}$ & $\begin{array}{l}\text { Altitud } \\
\text { en metros }\end{array}$ & Estaciones & Ramales \\
\hline 0 & 34 & Antofagasta & \\
\hline 4 & 60 & Playa Blanca & \\
\hline 14 & 295 & Sgto. Aldea & \\
\hline 21 & 408 & La Negra & $\begin{array}{l}\text { Arranque hacia cantón A. } \\
\text { Blancas }\end{array}$ \\
\hline 29 & 554 & Portezuelo & \\
\hline 35 & 561 & O'Higgins & $\begin{array}{l}\text { Of. Savona, Pissis y Domeyko. } \\
\text { Arranque hacia Boquete }\end{array}$ \\
\hline 48 & 573 & Uribe & \\
\hline 59 & 682 & Prat & \\
\hline 70 & 783 & Latorre & \\
\hline 83 & 893 & Cuevitas & \\
\hline 96 & 1.014 & Baquedano & $\begin{array}{l}\text { Of. Ercilla, Astoreca, J. F. } \\
\text { Vergara }\end{array}$ \\
\hline 109 & 1.164 & Cerrillos & \\
\hline 117 & 1.231 & El Buitre & Of. Sgto. Aldea. \\
\hline 120 & 1.279 & Santa Rosa & \\
\hline 122 & 1.285 & Carmen Alto & Of. F. Puelma, Condell, Celia \\
\hline 128 & 1.341 & Salinas & $\begin{array}{l}\text { Of. Lastenia, Aurelia, Carmela } \\
\text { Blanco Encalada }\end{array}$ \\
\hline 133 & 1.369 & Peineta & Of. Ausonia, Cecilia \\
\hline 136 & 1.383 & Central & Of. A. Edwards \\
\hline 144 & 1.414 & Unión & $\begin{array}{l}\text { Of. Anita, Candelaria, Luisis } \\
\text { Angamos, Araucana }\end{array}$ \\
\hline 148 & 1.431 & Placilla & Of. María, Curicó \\
\hline 154 & 1.470 & Solitario & Of. Filomena, Perseverancia \\
\hline $\begin{array}{l}162 \\
170\end{array}$ & $\begin{array}{l}1.534 \\
1.623\end{array}$ & La Noria & $\begin{array}{l}\text { Of. Aconcagua } \\
\text { Sierra Gorda Arranque para } \\
\text { Caracoles }\end{array}$ \\
\hline
\end{tabular}


Cuadro $\mathrm{N}^{\circ} 2$

(CONTINUACIÓN)

\begin{tabular}{|c|l|l|l|}
\hline $\begin{array}{c}\text { Kilómetros } \\
\text { desde Antofagasta }\end{array}$ & $\begin{array}{c}\text { Altitud } \\
\text { en metros }\end{array}$ & Estaciones & \multicolumn{1}{|c|}{ Ramales } \\
\hline 179 & 1.727 & Cochrane & \\
205 & 2.142 & Cerritos Bayos & \multirow{2}{*}{ A Chuquicamata y El Abra } \\
238 & 2.265 & Calama & \\
269 & 2.641 & Cere & \\
299 & 3.015 & Conchi & \\
312 & 3.223 & San Pedro & \\
340 & 3.772 & Polapi & \\
360 & 3.955 & Ascotán & \\
387 & 3.729 & Cebollar & \\
412 & 3.692 & San Martín & A Collahuasi \\
435 & 3.696 & Ollagüe & . \\
\hline
\end{tabular}

Fuente: Elaboración propia.

Calama en el tiempo se convirtió en el principal punto de partida del servicio de pasajeros con destino hacia La Paz.

Un segundo hito se vinculó a los ferrocarriles de Taltal. Inicialmente Alfredo QuaetFaslem obtuvo una concesión en marzo de 1880 para unir Taltal con Refresco, a veinte kilómetros de Agua Verde. La demora en la ultimación de la obra le obligó a transferir sus derechos a Jorge Stevenson, quien constituyó en junio de 1881 The Taltal Railway Company Ltd., y verificó la obra. Un testimonio contemporáneo anónimo (1894) puso de relieve la proeza al enfatizar la carencia de estudio en el área. El empuje ferroviario guardó conexión con la revalorización de las pertenencias salitreras en el cantón de Taltal. En 1890 la Cía. Salitrera Santa Luis construyó un ferrocarril entre las oficinas Guillermo Matta y Santa Catalina del Norte.

El tercer hito fue la prolongación de la red norte de los ferrocarriles del Estado desde Pueblo Hundido hasta la provincia de Tarapacá, cuyo examen comenzó con el nuevo siglo. En la Cámara de Diputados en junio de 1907 se debatió la conveniencia por el Estado de seguir impulsando los denominados "ferrocarriles regionales".
Después de varios intentos fallidos en los años 1905-1909 sobre la viabilidad del tendido ferroviario, el gobierno aceptó el 25 de octubre de 1909 la propuesta de J.J. Williams, representante de la firma británica Chilian Longitudinal Railway Construction Co. Ltd., que después de algunos contratiempos en los contratos traspasó sus derechos a Chilian Northern Railway Co. Ltd., en agosto de 1910. El gobierno aprobó aquello en junio de 1911. El destino era Ilegar hasta Pintados, teniendo como punto de intercambio la estación de Baquedano para el intercambio con el F.C.A.B. El 10 de enero de 1914 el Longitudinal Norte nacía 7 .

El último hito fue el esfuerzo mancomunado de Antofagasta y Salta por concretar un tendido ferroviario entre ambas ciudades. La idea abarcó entre 1906 y 1948, en-

\footnotetext{
7 El especialista en nuestros ferrocarriles Ian Thomson (Thomson, 2003) refiere que el ferrocarril longitudinal debió afrontar enormes desafíos, atravesar una de las zonas más áridas del mundo, la producción agrícola era nula, población inexistente y muy limitada en sus ciudades pequeñas, escaso volumen de su producción minera y expectativas muy limitadas de transportar tráficos de largo recorrido hacia y desde las zonas central y sur del país.
} 
tre proyectos, avances, convenios e inauguración del ferrocarril. Un precursor fue Manuel Solá quien en 1906 publicó su estudio "Ferrocarril trasandino de Salta a Mejillones o Antofagasta".

En la capital de provincia se estableció un Comité Pro Construcción del FF.CC. de Antofagasta a Salta, que llevó a cabo diversos comicios públicos en la década de 1920 (González Pizarro, 2002; Thomson, 2003). Cuando se inauguró el ferrocarril de Antofagasta a Salta por Juan Domingo Perón en 1948 las expectativas cifradas se habían esfumado.

Un punto complementario a los hitos referidos fue el destino que le cupo a los ferrocarriles salitreros y cupreros, después de la crisis del salitre del sistema Shanks. The Anglo-Chilean Nitrate Co. electrificó el ferrocarril de Tocopilla al Toco en 1927, empero, la vía hacia el Toco fue cerrada en 1957. The Chile Exploration Co. Railway construyó un ferrocarril entre Chuquicamata y San Salvador, que electrificó en 1925. El F.C.A.B. estandarizó la trocha de sus vías en 1928 desde 762 a 1.000 mm, y durante esta década y la siguiente vio circular pequeños carros impulsados por velas que trasladaban a empleados. La singularidad fue apreciada por Isaiah Bowman en su "Desert Trails of Atacama" que publicó un testimonio gráfico en 1924.

\section{El vuelo sobre la inmensidad: Aviones y pistas}

La aviación comercial en Chile comenzó con el D.L.N 413 del 9 de marzo de 1925 pero la fecha que marcó su impulso definitivo fue el 5 de marzo de 1929, con la creación de la Línea Aeropostal Santiago-Arica, cuyo soporte fue el personal formado por la aviación militar (Miranda, 1962).

El 21 de enero de 1929 diez aeroplanos Moth despegaron desde El Bosque rumbo hacia Arica. De los tres que sufrieron accidentes, el último del capitán Acuña cayó a treinta kilómetros de Portezuelo, en la comuna de Antofagasta. Portezuelo fue la pista de aterrizaje del vuelo inaugural de la Línea Aeropostal, donde el teniente Carlos Baldeig cubrió la distancia entre Antofagasta e Iquique (Salsilla, 1972).

El Estado creó la Línea Aérea Nacional el 21 de julio de 1932. La ruta entre SantiagoArica consideró una detención en Portezuelo.

El territorio desértico se transformó en una ruta aeropostal y de pasajeros/carga. La importancia económica de la región y la actividad técnica y administrativa superior de la actividad minera reforzó la conveniencia con la modernización de los medios de conectividad en la región. Los habitantes de la zona organizaron en 1940 el Club Aéreo de Antofagasta.

La construcción de las pistas de aterrizaje quedó condicionada a tres variables. Una, la capacidad fiscal de inversión en una infraestructura mínima, dos, la exigencia de las máquinas de aeronavegación para sus vuelos de aterrizaje/despegue regulares y tres, el volumen de carga y de pasajeros con destinos nacional e internacional.

Portezuelos, lugar localizado en la depresión intermedia, se constituyó en la primera pista aérea, incluso antes de la aviación comercial, pues hacia 1924 aterrizaron aviones como lo comprueban varias fotografías de la época.

En agosto de 1935 el gobierno de Alessandri destinó fondos para la construcción y mejoramiento de un aeropuerto pero en la ciudad. La Chimba, al norte de la ciudad, fue elegida como nuevo aeródromo al servicio de LAN, entrando en funcionamiento en 1941.

La estrechez de la pista movió a la Dirección de Aeronáutica a definir otro lugar como aeropuerto en 1945, entregando la pista de La Chimba al Club Aéreo y emprendiendo los estudios del aeropuerto de Cerro Moreno.

En 1954 entró en funciones el aeropuerto de Cerro Moreno para el servicio de la F.A.Ch. y para la aviación comercial.

La relevancia del mineral de Chuquicamata decidió al gobierno habilitar una pista en la ciudad de Calama en 1952. En 1955 
se entregó la losa del aeropuerto de Calama y en 1957 se inauguró la pista asfaltada del aeródromo El Loa de Calama.

La actividad salitrera de las oficinas Pedro de Valdivia y María Elena demandó contar en sus proximidades con pistas de aterrizajes. Un pequeño aeródromo que atendió a Tocopilla a las faenas salitreras fue Barriles -próximo a la estación ferroviaria homónima- construido hacia fines de la década de 1940. En los años 50 operó en ella la línea aérea "Cóndor". En 1958 la Compañía Anglo-Lautaro construyó una pista de aterrizaje que denominó "Pablo F. Krüger", cercana a la oficina María Elena para el servicio aéreo de un avión Stinson Reliant, bautizado como "El Calichera", que hizo el recorrido diario entre la usina y Antofagasta para abastecer a los pampinos con leche de vaca y pescado (Pampa, 1958).

Al comenzar la década de 1960 Taltal se incorporó al tráfico aéreo con una pista pavimentada, el aeródromo Las Breas. Por otro lado, el nuevo aeropuerto de Antofagasta posibilitó proyectar viajes por la aerolínea Panagra entre Antofagasta y Salta. En 1967 la Línea Aérea del Cobre -Ladeco- inauguró sus vuelos entre las mismas ciudades.

\section{Consideraciones finales}

La relación del Hombre y el desierto se dio en una lógica de desafío. Fue el Hombre el que designó los lugares y aportó su toponimia regional. El conocimiento que tuvo del territorio guardó relación con variadas finalidades que ayudaron a establecer la conectividad.

El territorio constituyó una valla natural. Sin embargo, la estructura cognitiva que el Hombre desplegó sobre el desierto de Atacama pasó de la cósmica-sacra, vinculada a los pueblos originarios que conectaron las tierras altas con la costa, a la lógica del dominio tanto técnico como de explotación de los recursos mineros, propio del desarrollo del capitalismo.

La región vio la implementación de la conectividad desde tiempos precolombinos en la costa y en las rutas caravaneras; realidad que fue aprovechada por la administración hispana.
El legado de las experiencias coloniales fue asumido por la llegada de la república. El territorio vio desmembrarse la unidad constituida históricamente de su conectividad con la hoya altiplánica. Razones de seguridad nacional y más tarde conveniencias comerciales y convenios internacionales, exigieron volver a rastrear la conectividad. La realidad de los contactos internacionales y el proceso de modernización condujeron a la conquista del espacio y al surgimiento de los aeródromos.

La trama de la cultura y la naturaleza en esta conectividad refiere de variados factores e intereses, tanto privados como estatales, y el imperativo de mejoramiento de los materiales empleados.

Paradójicamente, aunque el hombre desertara del páramo, dejó la impronta de su huella en el desierto. Reliquias patrimoniales que refieren de su mentalidad y tecnología aplicadas a su visión de la naturaleza.

\section{Referencias bibliográficas}

A.I.A. - ARCHIVO INTENDENCIA DE ANTOFAGASTA (ARCHIVO NACIONAL). Oficios del Ingeniero de la Provincia de 17 de junio y 2 de julio de 1926, Vol. 46 Antofagasta: A.I.A, 1926.

A.I.A. - ARCHIVO INTENDENCIA DE ANTOFAGASTA (ARCHIVO NACIONAL). Memoria del servicio de caminos de la provincia de Antofagasta correspondiente al año 1934, Vol. 147. Antofagasta: A.I.A, 1934a.

A.I.A. - ARCHIVO INTENDENCIA DE ANTOFAGASTA (ARCHIVO NACIONAL). Oficio Gerente de la Compañía Sudamericana de Vapores, de 10 de noviembre de 1934, al Director del Litoral, Vol. 149. Antofagasta: A.I.A, 1934b.

AGUIRRE ZAVALA, J. Proyecto para la construcción de un camino carretero entre Cobija y Alto de Tames en la dirección de Calama y Caracoles. Valparaíso: Imprenta del Mercurio, 1871.

ANGUITA, R. Leyes promulgadas en Chile. Santiago de Chile: Imprenta, Litografía i Encuadernación Barcelona, 1912. 
ANÓNIMO. Algunas historias ferrocarrileras de Chile y el ingeniero civil J. Harry Thomas miembro de la institución de ingenieros civiles de Inglaterra. Aclaraciones y publicación necesaria sobre varios puntos. Santiago de Chile: Imprenta Cervantes, 1894.

ARCE, I. Narraciones históricas de Antofagasta. Antofagasta: Imprenta Moderna, 1930.

BAKER, A. Geography and History. Bridging the Divide. Cambridge: Cambridge Studies in Historical Geography, University Press, 2003.

BENAVIDES, J.; VALENZUELA, M. P. y PIZZI, M. Ciudades y arquitectura portuaria. Los puertos mayores del litoral chileno. Santiago de Chile: Editorial Universitaria, 1994.

BERMÚDEZ MIRAL, O. Orígenes históricos de Antofagasta. Santiago de Chile: Imprenta Universitaria, 1966.

BERMÚDEZ MIRAL, O. Historia del Salitre, desde la Guerra del Pacífico hasta la Revolución de 1891. Santiago de Chile: Ediciones Pampa Desnuda, 1984.

BERTRAND, A. Memoria sobre las cordilleras del desierto de Atacama i rejiones limítrofes. Santiago de Chile: Imprenta Nacional, 1885.

BITTMAN, B. Notas sobre las poblaciones de la costa del norte grande chileno. In: CASSASAS CANTÓ, J. Aproximaciones a la Etnohistoria del Norte de Chile y Tierras Adyacentes. Antofagasta: Universidad del Norte, 1977, p. 56-115.

BITTMAN, B. Cobija: Proyecto de investigaciones interdisciplinarias en la costa centro-sur andina (Chile). Antofagasta: Universidad del Norte, 1980, Vol. I.

BLAKEMORE, H. Historia del Ferrocarril de Antofagasta a Bolivia. 1888-1988. Traducción de Juan Ricardo Couyoumdjian y Beatriz Kase. Santiago de Chile: Impresos Universitaria S.A., 1996.

BOWMAN, I. Desert Trails of Atacama. New York: American Geographical Society, 1924.
BRAUDEL, F. La historia y las ciencias sociales. Madrid: Alianza Editorial, 1970.

BRAUDEL, F. El Mediterráneo y el mundo mediterráneo en la época de Felipe II. México: Fondo de Cultura Económica, 2005, Tomo I.

BRESSON, A. Una visión francesa del litoral boliviano (1886). La Paz: Stampa Gráfica Digital, 1997.

BULL, F. Caminos de Antofagasta. In: UNIVERSIDAD DE CHILE. Seminario Problemas Regionales de Antofagasta. Santiago de Chile: Edición Departamento de Extensión Cultural, 1957.

CABEZAS, F. Jama, el paso de la esperanza. In: MORA, O. y ROMERO, P (Comps.). Noa-Norte Grande. Crónica de dos regiones integradas. Santiago de Chile: Embajada de Chile en Argentina, 1999, p. 76-81.

CAJÍAS, F. La provincia de Atacama (1825-1842). La Paz: Imprenta Universo, 1975.

CÁMARA DE DIPUTADOS. Legislatura Extraordinaria 1883-1884. Santiago de Chile: Imprenta Nacional, 1884.

CÁMARA DE DIPUTADOS. Legislatura Ordinaria 1887. Santiago de Chile: Imprenta Nacional, 1887.

CÁMARA DE DIPUTADOS. Legislatura Extraordinaria 1889. Santiago de Chile: Imprenta Nacional, 1889.

CÁMARA DE DIPUTADOS. Legislatura Extraordinaria 1892-1893. Santiago de Chile: Imprenta Nacional, 1892.

CÁMARA DE DIPUTADOS. Legislatura Ordinaria 1895. Santiago de Chile: Imprenta Nacional, 1895.

CÁMARA DE DIPUTADOS. Legislatura Ordinaria 1897. Santiago de Chile: Imprenta Nacional, 1897.

CÁMARA DE DIPUTADOS. Legislatura Ordinaria 1899. Santiago de Chile: Imprenta Nacional, 1899. 
CÁMARA DE DIPUTADOS. Legislatura Ordinaria 1901. Santiago de Chile: Imprenta Nacional, 1901.

CÁMARA DE DIPUTADOS. Legislatura Extraordinaria 1903-1904. Santiago de Chile: Imprenta Nacional, 1903.

CÁMARA DE DIPUTADOS. Legislatura Extraordinaria 1907-1908. Santiago de Chile: Imprenta Nacional, 1907.

CLARO SOLAR, R. et al. Comisión de Puertos. Puerto de Antofagasta. Proyecto de Mejoramiento. Santiago de Chile: Imprenta Universitaria, 1913.

CONTI, V. El norte argentino y Atacama: producción y mercados. Revista de Historia. Segunda Época, 1993, № 14, p. 7-38.

CONTI, V. La ruta de los arrieros y el salitre. In: CABEZAS, A. et al. Las rutas del capricornio andino. Huellas milenarias de Antofagasta, San Pedro de Atacama, Jujuy y Salta. Santiago de Chile: Consejo de Monumentos Nacionales, 2006, p. 93-104.

D'ORBIGNY, A. y BALLESTEROS, M. (Introd.). Viajes y viajeros: viajes por América del Sur. Madrid: Aguilar, 1958.

DE VIDTS, E. Proyecto de ciudad y de mejoramiento del Puerto de Mejillones por el ingeniero hidráulico don Emilio de Vidts. Valparaíso: Talleres Tipográficos de la Armada, 1906.

EDER, K. The Social Construction of Nature: A Sociology of Ecological Enlightenment. London: Sage Publications, 1996.

EL ABECÉ. Periódico de Antofagasta. El Abecé, 1947, edición 12 de noviembre.

ESPINOZA, E. Geografía descriptiva de la República de Chile. Santiago de Chile: Imprenta Litografía i Encuadernación Barcelona, 1903.

GARCÉS FELIÚ, E. Las ciudades del salitre: estudio de las Oficinas Salitreras en la región de Antofagasta. Santiago de Chile: Orígenes, 1999.
GALLARDO NIETO, G. Ferrocarriles salitreros de Tarapacá. Santiago de Chile: Imprenta Universitaria, 1911.

GLACKEN, C. Environment and Culture. In: PHILIP, P. (Ed.). The Dictionary of the History of Ideas. New York: Charles Scribner's Sons, 1973, p. 127-134.

GONZÁlEZ PIZARRO, J. La Iglesia y la Revolución de 1891 en Antofagasta. Antofagasta: Ediciones Taller de Literatura Recital, 1980.

GONZÁLEZ PIZARRO, J. Las estrategias económicas regionales de Antofagasta en la década de 1930. Revista de Ciencias Sociales - Unap, 1999, № 9, p. 23-44.

GONZALEZ PIZARRO, J. Espacio y política en Antofagasta en el ciclo salitrero. La percepción del desierto y el sentimiento regionalista, 1880-1930. In: CONTI, V. y LAGOS, M. Una Tierra y tres naciones. El litoral salitrero entre 1830 y 1930. Jujuy: Universidad Nacional de Jujuy, 2002, p. 251-290.

GONZÁLEZ PIZARRO, J. La pampa salitrera en Antofagasta. La vida cotidiana durante los ciclos Shanks y Guggenheim en el desierto de Atacama. Antofagasta: Corporación Pro Antofagasta, 2003.

GONZÁLEZ PIZARRO, J. Vialidad moderna. In: CABEZAS A. et al. Las rutas del capricornio andino. Huellas milenarias de Antofagasta, San Pedro de Atacama, Jujuy y Salta. Santiago de Chile: Consejo de Monumentos Nacionales, 2006, p. 151-163.

GONZALEZ PIZARRO, J. Imaginarios contrapuestos: el desierto de Atacama percibido desde la región y mirado desde la nación (su construcción a través del tiempo). Manuscrito, 2008. En vías de publicación.

GRINZER, N. The Classical Nature-Convention Opposition. A Contemporary Perspective. In: LARSEN, S \& GRGAS, S. The Construction of Nature. A Discursive Strategy in Modern European Thought. Estonia: Zooloogia ja Botaanika Instituut, 1992. Disponible en Internet: www.zbi.ee/-kalevi/ larsen.htm-506k 
INTER-AMÉRICA. Chile Industrial, Comercial, Social "Guía General de Chile", año 1924. Santiago: Inter-América, 1924.

IRIBARREN, J. y BERGHOLZ, H. EI Camino del Inca en el sector del Norte ChicoUna mina de explotación. La Serena: Colección 11 de julio, 1971.

LASTARRIA, A. Informe sobre vías de comunicación y manera de desarrollar la industria en el desierto de Atacama. Santiago de Chile: S:P:I., 1880.

LASTARRIA, J. V. Caracoles. Cartas descriptivas sobre este importante mineral dirigidas al Sr. Tomás Frías, Ministro de Hacienda de Bolivia. Valparaíso: Imprenta de la Patria, 1871

MARTÍNEZ, J. L. Dispersión y movilidad en Atacama Colonial. In: SILVA GALDAMES, O. et al. ¿Etnohistoria o historia indígena? Encuentro de Etnohistoriadores. Santiago de Chile: Serie Nuevo Mundo. Cinco Siglos Universidad de Chile, 1982, p. 53-69.

MIRANDA, O. Transportes. In: CORFO. Geografía Económica de Chile. Santiago de Chile: Corporación de Fomento a la Producción, 1962, Tomo IV.

MORRISON, A. The Tranways of Chile 1858-1978. Traducido por Marcelo Madariaga. Nueva York: Bonde Press, 1992. Disponible en Internet: http://www.tranvias dechile.cl/am.htm

MOSCOVICl, S. El psicoanálisis, su imagen y su público. Buenos Aires: Huemal, 1979.

MUÑIZ SOLARI, O. Geografía del Transporte y Comunicaciones. Santiago de Chile: Instituto Geográfico Militar, 1985.

NúÑEZ, L. Balsas prehistóricas del litoral chileno: Grupos, funciones y secuencia. Antofagasta: Universidad del Norte, 1979.

NÚÑEZ, L. Tráfico de complementaridad de recursos entre las tierras altas y el Pacífico en el área centro sur andina. Tokio: Universidad de Tokio, Departamento de Antropología Cultural, 1984. Vol. II. Tesis Doctoral Inédita.
NúÑEZ, L. y DILLEHAY, T. Movilidad giratoria, armonía social y desarrollo en los Andes Meridionales: Patrones de tráfico e interacción económica. Ensayo. Antofagasta: Universidad Católica del Norte, 1995.

PAMPA. Revista Pampa editada en Antofagasta. Pampa, 1958, edición julio, Nº 124.

PANADÉS VARGAS, J. et al. Mejillones, un pueblo con historia. Antofagasta: Servicios Gráficos Ltda., 1995.

PANADÉS VARGAS, J y GONZÁLEZ PIZARRO, J. Antofagasta, historia de mi ciudad. Antofagasta: Corporación Pro Antofagasta, 1998.

PHILIPPI, R. Viage al Desierto de Atacama hecho de orden del Gobierno de Chile en el verano 1853-54. Halle-Sajonia: Librería de Eduardo Anton, 1860.

QUINTANILLA, V. Diccionario de Biogeografía para América Latina. Valparaíso: Ediciones Universitarias de Valparaíso, 1977.

RAFFINO, R. El capricornio inka: la unificación política. In: CABEZAS, A. et al. Las rutas del capricornio andino. Huellas milenarias de Antofagasta, San Pedro de Atacama, Jujuy y Salta. Santiago: Consejo de Monumentos Nacionales, 2006, p. 67-77.

REYES, E. Baburizza Lagarrigue y Cía. Obras en construcción del Puerto de Antofagasta. Santiago de Chile: Editorial Nascimento, 1928.

ROSSI, G. Tocopilla. Reseña histórica y desarrollo urbano. Tocopilla: Norgener, 1993.

RUIZ, M. Los Inkas. Espacio y Cultura. San Salvador de Jujuy: Universidad Nacional de Jujuy, 1998.

SAGREDO, R. La gira del presidente Balmaceda al norte. El inicio del "crudo y riguroso invierno de su quinquenio" (verano de 1889). Santiago de Chile: Universidad Arturo Prat - Centro de Investigaciones Diego Barros Arana, 2001.

SALSILLA, V. Historia de la aviación chilena. Santiago de Chile: Editorial Quimantú, 1972. 
SAUER, C. The Morphology of Landscape. Traducción al español de Guillermo Castro. University of California Publications in Geography, 1925, Vol. 2, $\mathrm{N}^{\circ} 2$, p. 19-53. Disponible en Internet: http://www.colo rado.edu/geography/giw/sauer-co/sauerco.html

SAUER, C. Foreword to historical geography. Annals of the Association of American Geographers, 1941, Vol. 31, p. 1-24. Traducción al español de Guillermo Castro. Disponible en Internet: http://www.colo rado.edu/geography/giw/sauer-co/sauerco.html

SAUER, C. The Agency of Man on the Earth. In: THOMAS, W. Man's Role in Changing the Face of the Earth. Chicago: University of Chicago Press, 1956, p. 49-69. Traducción al español de Guillermo Castro. Disponible en Internet: http://www.colo rado.edu/geography/giw/sauer-co/sauerco.html

SOCIEDAD ANÓNIMA. Transferencias del Ferrocarril y Puerto de Coloso, Libro de Títulos $\mathrm{N}^{\circ}$ 4. Antofagasta: Imprenta MacFarlane, 1930.

STEHBERG, R. Instalaciones incaicas en el norte y centro semiárido de Chile. Santiago de Chile: Dibam - Centro de Investigaciones Diego Barros Arana, 1995.
SWETT, R. Guía Marítima de Chile años 1923-1924. Valparaíso: S.P.I., 1924.

THOMSON, I. La Red Norte: La historia de los ferrocarriles del norte chileno. Santiago de Chile: Imprenta Silva, 2003.

VALENZUELA, J. Álbum Zona Norte de Chile. Santiago de Chile: S.P.I., 1926.

VIDAL GORMAZ, F. Geografía Náutica de la República de Chile. Cap. XVI. Entre el grado 24 i el grado 23. Anuario Hidrográfico de la Marina de Chile, 1880, Año VI, N6, p.V y ss.

VIDAL GORMAZ, F. Geografía Náutica de la República de Chile. Cap. XVI. Entre el grado 24 i el grado 23. Anuario Hidrográfico de la Marina de Chile, 1881, Año VII, N 7 , p.139-164.

VIDAL GORMAZ, F. Primera parte. Esploraciones hidrográficas practicadas a las costas de Chile por la Marina Militar de la República. Geografía Náutica de la República de Chile. Anuario Hidrográfico de la Marina de Chile, 1884, Año X, p. 5-12.

WORSTER, D. Haciendo Historia Ambiental. In: WORSTER, D. (Ed.). The Ends of the Earth. Perspectives on Modern Environmental History. New York: Cambridge University Press, 1989. 